\title{
Identification of Mammalian Noggin and Its Expression in the Adult Nervous System
}

\author{
David M. Valenzuela, ${ }^{1}$ Aris N. Economides, ${ }^{1}$ Eduardo Rojas, ${ }^{1}$ Teresa M. Lamb, ${ }^{4}$ Lorna Nuñez, ${ }^{1}$ Pam Jones, ${ }^{1}$ \\ Nancy Y. Ip, ${ }^{1}$ Rafael Espinosa III, ${ }^{2}$ Camilynn I. Brannan,, ${ }^{3}$ Debra J. Gilbert, ${ }^{3}$ Neal G. Copeland, ${ }^{3}$ Nancy A. \\ Jenkins, ${ }^{3}$ Michelle M. Le Beau, ${ }^{2}$ Richard M. Harland, ${ }^{4}$ and George D. Yancopoulos ${ }^{1}$ \\ ${ }^{1}$ Regeneron Pharmaceuticals, Inc., Tarrytown, New York 10591, ${ }^{2}$ Section of Hematology/Oncology, Department of \\ Medicine, University of Chicago, Chicago, Illinois 60637, ${ }^{3}$ Mammalian Genetics Laboratory, ABL-Basic Research \\ Program, NCl-Frederick Cancer Research and Development Center, Frederick, Maryland 21702, ${ }^{4}$ Department of \\ Molecular and Cell Biology, University of California, Berkeley, California 94720
}

\begin{abstract}
The multiple roles of noggin during dorsal fate specification in Xenopus embryos, together with noggin's ability to directly induce neural tissue, inspired an effort to determine whether a similar molecule exists in mammals. Here we describe the identification of human and rat noggin and explore their expression patterns; we also localize the human NOGGIN gene to chromosome 17q22, and the mouse gene to a syntenic region of chromosome 11. Mammalian noggin is remarkably similar in its sequence to Xenopus noggin, and is similarly active in induction assays performed on Xenopus embryo tissues. In the adult mammal, noggin is most notably expressed in particular regions of the nervous system, such as the tufted cells of the olfactory bulb, the piriform cortex of the brain, and the Purkinje cells of the cerebellum, suggesting that one of the earliest acting neural inducers also has important roles in the adult nervous system.
\end{abstract}

[Key words: noggin, neural inducer, Spemann organizer, Nieuwkoop center, dorsalization, olfactory bulb, Purkinje cells]

Developmental biologists have long been concerned with the mechanistic basis of inductive events that shape early embryogenesis. One particularly intriguing experiment performed over 70 years ago revealed that a small piece of tissue from the dorsal mesodermic region of the early salamander embryo, known as the Spemann organizer, can induce a second headto-tail body axis when ectopically positioned in the ventral half of a recipient embryo (Spemann et al., 1924; Spemann, 1938). Recent studies have identified a number of secreted proteins that may play roles in this and other early inductive events. One such protein is noggin, which was originally cloned based on its ability to restore a normal dorsal-ventral body axis in Xenopus embryos that had been artificially ventralized (Smith

\footnotetext{
Received Nov. 28, 1994; revised Apr. 27, 1995; accepted May 2, 1995.

We thank Dr. L. S. Schleifer and the entire Discovery Group at Regeneron for their enthusiastic support and insightful scientific input. We thank Dr. Stan Wiegand for discussion of the in situ hybridization results and Jennifer Griffith, Yuan Kong, Li Pan, Nestor Barrezueta, and Brian Cho for excellent technical assistance and Claudia Murphy for graphic work. This work was supported in part by PHS Grant CA40046 (MML) and the National Cancer Institute, DHHS, under contract NO1-CO-74101 with ABL.

Correspondence should be addressed to David M. Valenzuela, Regeneron Pharmaceuticals, Inc., 777 Old Saw Mill River Road, Tarrytown, NY 10591. Copyright $(1995$ Society for Neuroscience $0270-6474 / 95 / 156077-08 \$ 05.00 / 0$
}

et al., 1992). Maternally encoded noggin may play a role in dorsal fate specification during Xenopus embryogenesis as part of the early-acting Nieuwkoop center (Smith et al., 1992). The Nieuwkoop center is comprised by endodermal cells of the vegetal half of the embryo, and it induces dorsal mesoderm and formation of the Spemann organizer; noggin can mimic these effects of the Nicuwkoop center. Noggin is also subsequently expressed in the Spemann organizer, and can mimic its most important actions as well. For example, noggin can act during gastrulation to specify mesoderm to achieve more dorsal fates (e.g., to form muscle as opposed to blood and mesenchyme), and noggin can also act on isolated ectoderm tissue to directly induce formation of neural tissue (Lamb et al., 1993; Smith et al., 1993). Noggin on its own seemingly induces neural tissue of an anterior nature, but can act in combination with other signals to elicit more posterior neural fates, consistent with the notion that initial neuralization results in forebrain specification that is subsequentally caudalized to produce more posterior structures (Lamb et al., 1993).

The intriguing actions of noggin during dorsal fate specification and neural induction in Xenopus embryos raised the issue of whether a similar molecule exists in mammals. In addition, since noggin appears to be so pleiotropic early in development, we also wondered whether noggin might have additional actions later in life; a number of other factors, such as CNTF (Ip et al., 1993) and Wnt-3 (Salinas et al., 1994), have been shown to have functions both early in development as well as in later stages. Here we describe the identification of human and rat noggin and explore their expression patterns; we also localize the human and mouse NOGGIN genes. Mammalian noggin is remarkably similar in its sequence to Xenopus noggin, and is similarly active in induction assays performed on Xenopus embryo tissues. In the adult mammal, noggin is most notably expressed in the nervous system, suggesting that one of the earliest acting neural inducers also has important roles in the adult nervous system.

\section{Materials and Methods}

Cloning of mammalian Noggin genes and cDNAs. A partial mouse noggin cDNA clone was obtained using the Xenopus cDNA as a probe. This cDNA had an uncharacterized rearrangement but did display a short region of homology to the Xenopus noggin; oligonucleotide primers based on these conserved regions [the sequence of these $5^{\prime}$ (sense) and $3^{\prime}$ (antisense) primers were 5'-CAGATGTGGCTGTGGTCAC-3' (amino acids QMWLWS) and 5'-GCAGGAACACTTACACTCGG-3' 
H-Noggin

$\mathrm{x}$-Noggin

H-Nogg in

R-Noggin

$\mathrm{X}$-Noggin

$\mathrm{H}$-Noggin

R-Noggin

$\mathrm{X}$-Noggin

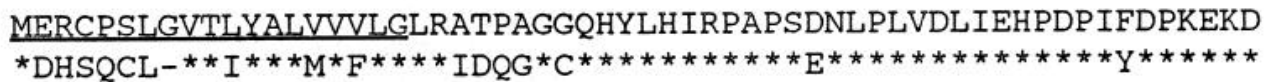

Variable Region I LNETLLRSLLGGHYDPGFMATSPPEDRPGGGGGAAGGAEDLAELDQLLRQRPSGAMPSEI 120

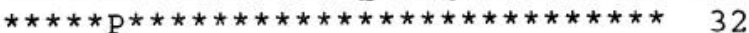

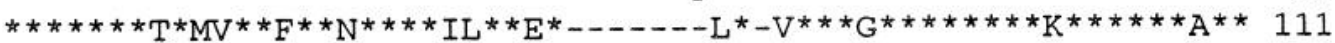
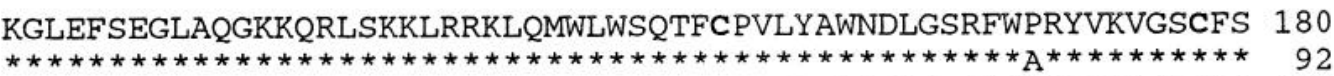

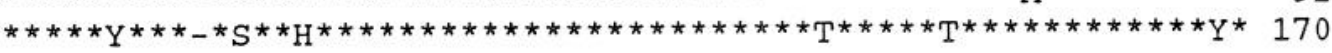

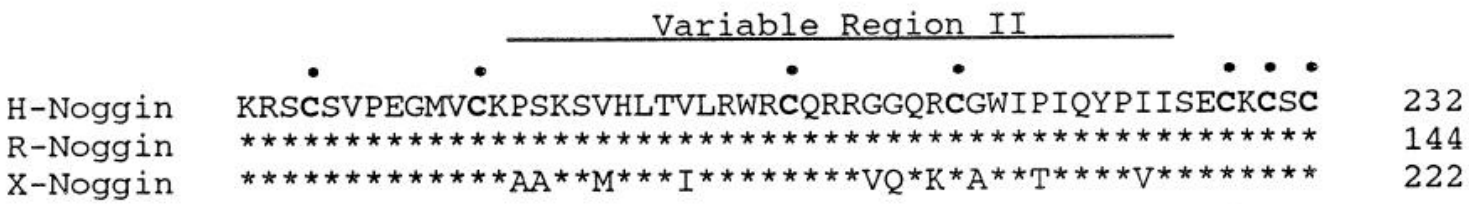

Figure 1. Comparison of human and rat noggin to Xenopus noggin. Asterisks indicate identity, dots over sequence indicate conserved cysteines. The signal peptide sequence is underlined, and "variable regions" are indicated.

(amino acids SECKCSC); see Fig. 1] were used to amplify a mouse probe used to identify clones from a human placental genomic library (Clontech Cat\#HL1067J), a human temporal cortex cDNA library (Stratagene Cat.\#935205 in Lambda ZAP), and a rat brain cDNA library (Stratagene, Cat.\#937502 prepared from brains of 14 and $16 \mathrm{~d}$ old male and female Sprague-Dawley rats). PCR probe preparation, library screening and DNA sequencing of clones were performed as previously described (Valenzuela et al., 1993). The human and rat noggin gene and cDNA sequences have been submitted to GenBank: accession numbers U31202 and U31203, respectively.

Noggin protein activity assay in Xenopus. Human or Xenopus noggin conditioned media from transfected COSm5 cells were diluted in a low $\mathrm{Ca}^{2+}$ and $\mathrm{Mg}^{2+}$ Ringer's solution, LCMR (Stewart et al., 1990), and used to treat St10 1/4 Xenopus ventral marginal zone tissue as described (Smith et al., 1993). Treated tissue was allowed to age to St20 and harvested for Northern analysis using a muscle actin probe. The conditioned media were generated as follows. The human noggin genomic clone and a Xenopus noggin cDNA clone were subcloned into an SV40-based mammalian expression vector and transfected into COSm5 cells using a DEAE/chloroquine based protocol (Davis et al., 1991). Conditioned media were collected 2 d after transfection, cleared of debris by centrifugation and sterile-filtered using a low protein binding $0.22 \mu \mathrm{m}$ cellulose acetate filter (Nalgene) and stored at $-20^{\circ} \mathrm{C}$ until use.

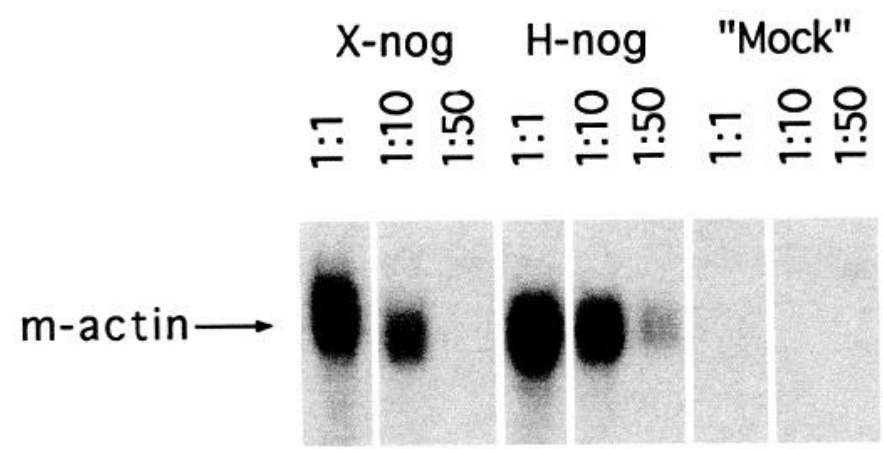

Figure 2. Dorsalizing activity of Xenopus and and human noggin in a ventral marginal zone (VMZ) assay. H-nog and X-nog refer to human and Xenopus noggin, respectively. The numbers indicate the dilutions of conditioned media used, resulting in 100,10, and $2 \mathrm{ng} / \mathrm{ml}$ of Xenopus and 400,40 , and $8 \mathrm{ng} / \mathrm{ml}$ of human noggin in each assay. "Mock" refers to conditioned medium from cells transfected with the expression vector without the noggin cDNA. The position of the muscle actin mRNA is shown.
Northern blotting analysis and in situ hybridization. Dissection of rat tissues, preparation of total RNAs and Northern blotting (using $10 \mu \mathrm{g}$ of total RNA per lane) was performed as described previously (Valenzuela et al., 1993). Amounts of RNA in the agarose gel were controlled by staining the gel with ethidium bromide. By this criteria all lanes shown in Figure 3 have approximately the same amount of RNA. A 280 bp PCR fragment containing the mouse noggin DNA sequence (to be described in more detail elsewhere) encompasing amino acids 146 to the termination codon (Fig. 1) was used as the probe for both Northern blotting and in situ hybridizations. For the latter, the probe was subcloned into Bluescript (KS+) for generating single-stranded RNA probes. ${ }^{35} \mathrm{~S}$-Radiolabeled antisense or sense strand probes were transcribed off linearized plasmids using a transcription kit from Promega. Coronal sections $(10 \mu \mathrm{m}$ thick) from adult rat brain were thawed, mounted into polylysine coated slides, and in situ hybridization was performed as described previously (Valenzuela et al., 1993).

Fluorescence in situ chromosomal hybridization. Human metaphase cells were prepared from phytohemagglutinin-stimulated peripheral blood lymphocytes. Fluorescence in situ hybridization was performed as described previously (Rowley et al., 1990). A biotin-labeled human NOGGIN genomic probe (hgNog $\lambda 10$ ) was prepared by nick-translation using Bio-11-dUTP (Enzo Diagnostics). Hybridization was detected with fluorescein isothiocyanate (FITC)-conjugated avidin (Vector Laboratories), and chromosomes were identified by staining with 4,6-diamino-2-phenylindole-dihydrochloride (DAPI)

Interspecific backcross mapping. Interspecific backcross progeny were generated by mating (C57BL/6J $\times M$. spretus) $\mathrm{F} 1$ females and C57BL/6J males (Copeland and Jenkins 1991). A total of 205 N2 progeny were obtained to map the Noggin locus (see text for details). DNA isolation, restriction enzyme digestion, agarose gel electrophoresis, Southern blot transfer were performed essentially as described (Jenkins et al., 1982). All blots were prepared with Hybond- $\mathrm{N}^{+}$nylon membrane (Amersham). The probe, a $280 \mathrm{bp} \mathrm{EcoRI/KpnI} \mathrm{fragment} \mathrm{from} \mathrm{the} \mathrm{mouse}$ Noggin clone in Bluescript (KS+) described above, was radiolabeled with ${ }^{{ }^{32} 2} \mathrm{P}-\mathrm{dCTP}$ using a random primer labeling kit (Stratagene); washing was done to a final stringency of $1.0 \times \mathrm{SSCP}, 0.1 \% \mathrm{SDS}, 65^{\circ} \mathrm{C}$. A major fragment of $13.0 \mathrm{~kb}$ was detected in HindIII digested C57BL/6J DNA and a major fragments of $15.0 \mathrm{~kb}$ was detected in HindIII digested $M$. spretus DNA. The presence or absence of the $15.0 \mathrm{~kb} \mathrm{M}$. spretusspecific HindIII fragment was followed in backcross mice.

A description of the probes and RFLPs for the loci linked to Noggin including myeloperoxidase $(\mathrm{Mpo})$, nerve growth factor receptor $(\mathrm{Ng} f \mathrm{r})$ and colony stimulating factor, granulocyte $(C s f g)$ has been reported previously (Buchberg et al., 1989). Recombination distances were calculated as described previously (Green, 1981) using the computer program SPRETUS MADNESS. Gene order was determined by minimizing the number of recombinant events required to explain the allele distribution patterns. 


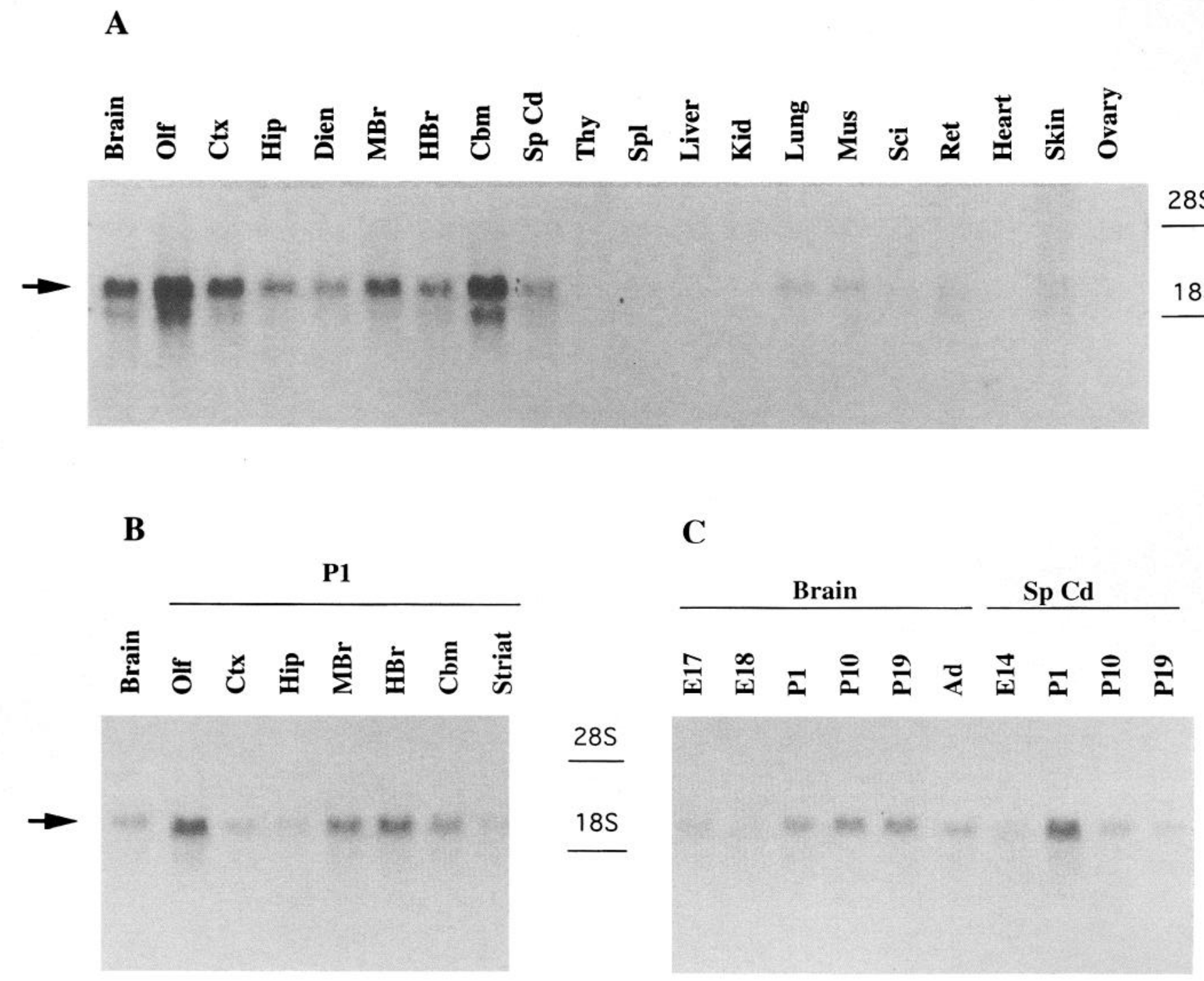

Figure 3. Northern blot analysis of the expression of noggin in the adult rat and during development. A, Noggin expression in rat adult neural and non-neural tissues. $B$, Noggin expression in newborn rat brain regions. $C$, Noggin expression in brain and spinal column at different developmental ages. Arrows indicate a 2.5 kb noggin transcript. $\mathrm{Cbm}$, cerebellum; $\mathrm{Ctx}$, cortex; Dien, diecephalon; $\mathrm{HBr}$, hindbrain; $\mathrm{Hip}$, hippocampus; Int, intestine; Kid, kidney; $M B r$, midbrain; Mus, muscle; Olf, olfactory bulb; Ret, retina; $S p C d$, spinal cord; Spl, spleen; $S c i$, sciatic nerve. Day of sperm positivity is designated as day E1, and day of birth is designated as day P1; Ad refers to tissue obtained from 6-8 week old adults.

\section{Results}

\section{Identification of human and rat noggin}

To clone mammalian counterparts to Xenopus noggin, we used the Xenopus noggin cDNA to screen a variety of genomic and cDNA libraries prepared from mammalian sources. This strategy eventually yielded a genomic clone encompassing the human NOGGIN gene, as well as a cDNA clone encoding the complete human noggin protein and a partial rat cDNA clone. Comparison of the human genomic and cDNA clones revealed that the noggin coding region is not interrupted by any introns, as both the genomic clone and the cDNA clone contained an open reading frame of 696 nucleotides that encoded a protein of 232 amino acids (Fig. 1). Human noggin displays $81 \%$ amino acid identity to Xenopus noggin, with most of the differences clustered within the signal peptide region and two additional "variable" regions (Fig. 1). The first of these two variable regions in human noggin contains a 7 amino acid insertion, including five glycines, as compared to the Xenopus version (Fig. 1). Sequence of the par- tial rat noggin cDNA fragment revealed the presence of the last 144 amino acids of rat noggin containing only two amino acid differences with human noggin (Fig. 1). Altogether, our cloning and analysis of human and rat noggin, and comparison to the Xenopus sequence, reveals that noggin is a highly conserved protein in vertebrates.

\section{Human noggin has inductive effects on Xenopus embryos}

To determine whether mammalian noggin retained the inductive capabilities of Xenopus noggin, we produced human noggin protein and compared it to Xenopus noggin for its ability to dorsalize ventral marginal zone tissue (Smith et al., 1993). The human noggin gave similar induction of muscle actin on Xenopus tissue as compared to Xenopus noggin (Fig. 2). These results reveal that the conservation in the structure of noggin between Xenopus and mammals underlies a conservation in the function of this protein. 

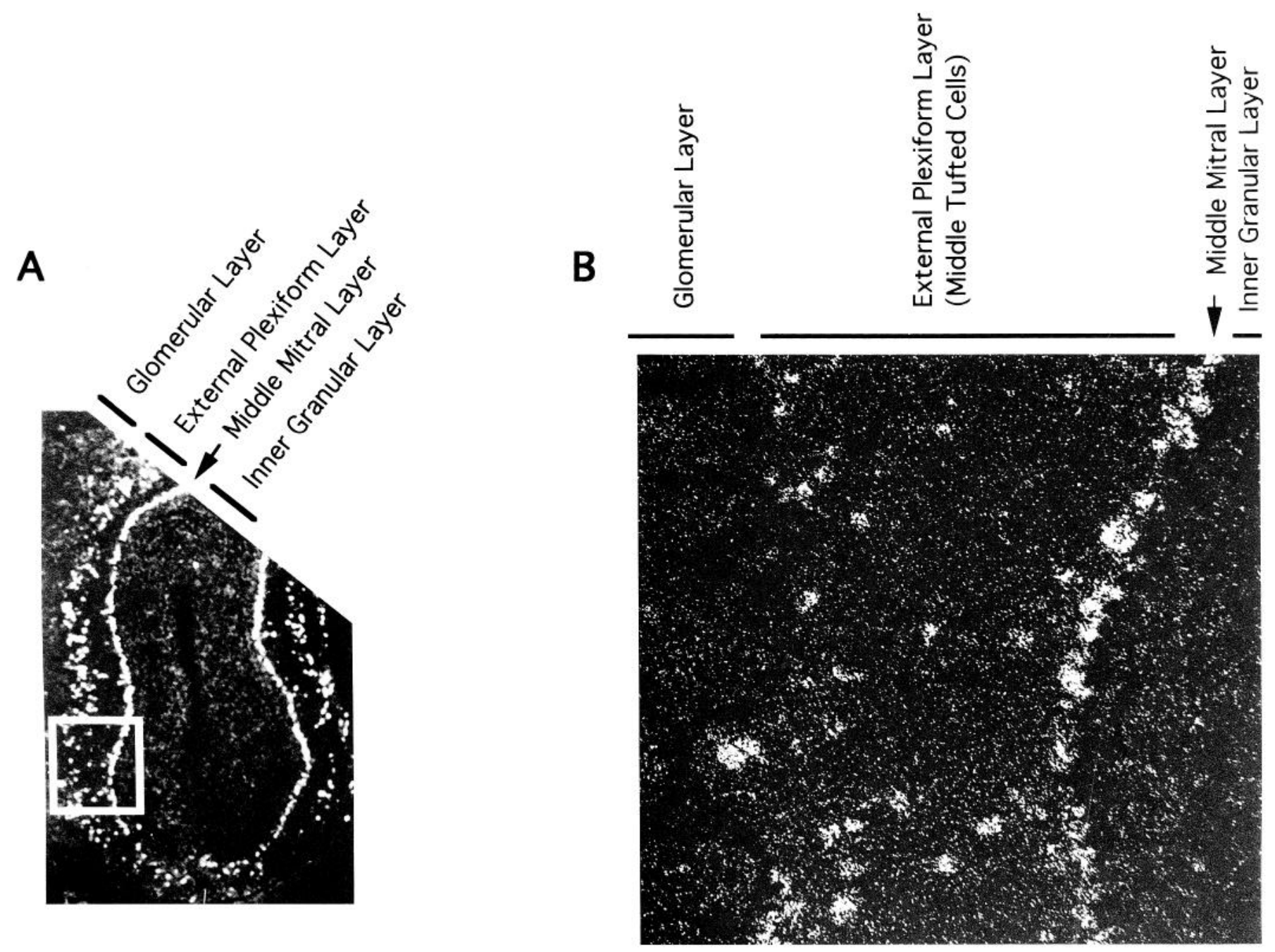

Figure 4. In situ localization of noggin transcripts in coronal section from adult rat olfactory bulb. $A$, Low magnification (20 $\times$ ); $B$, high magnification $(120 \times)$ of the area indicated in $A$.

A

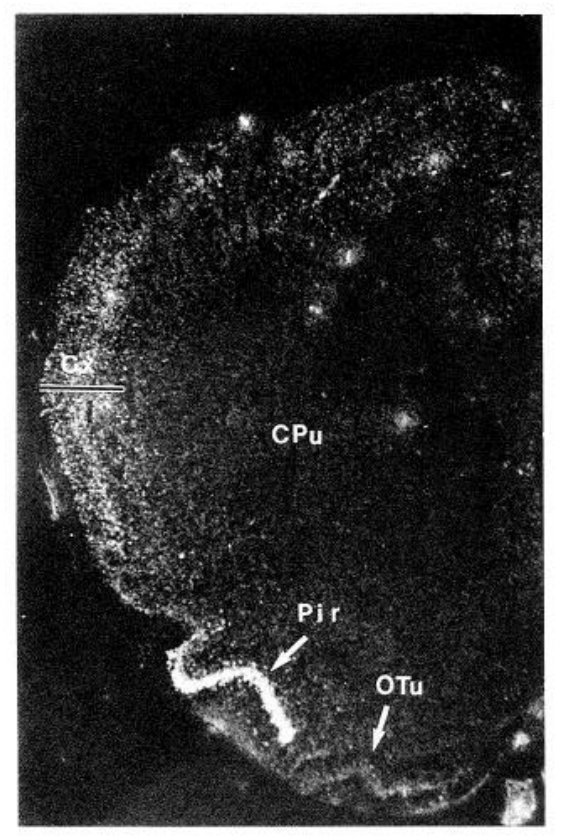

B

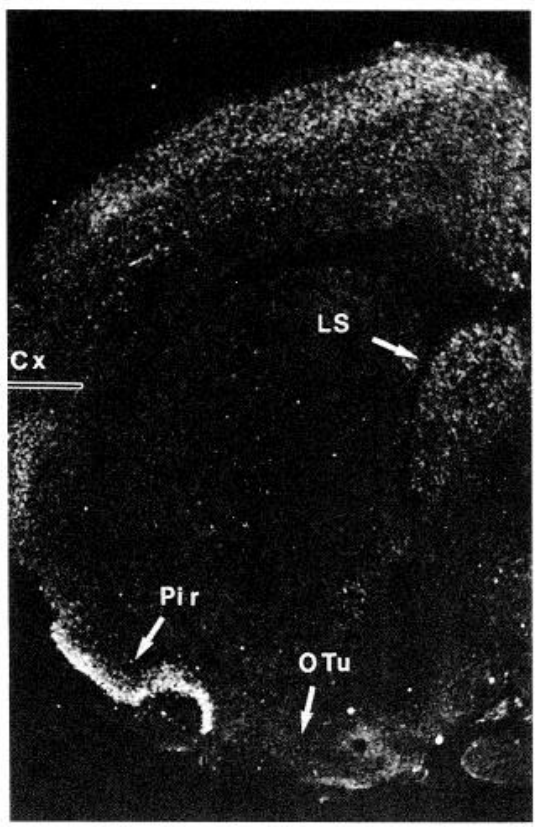

C

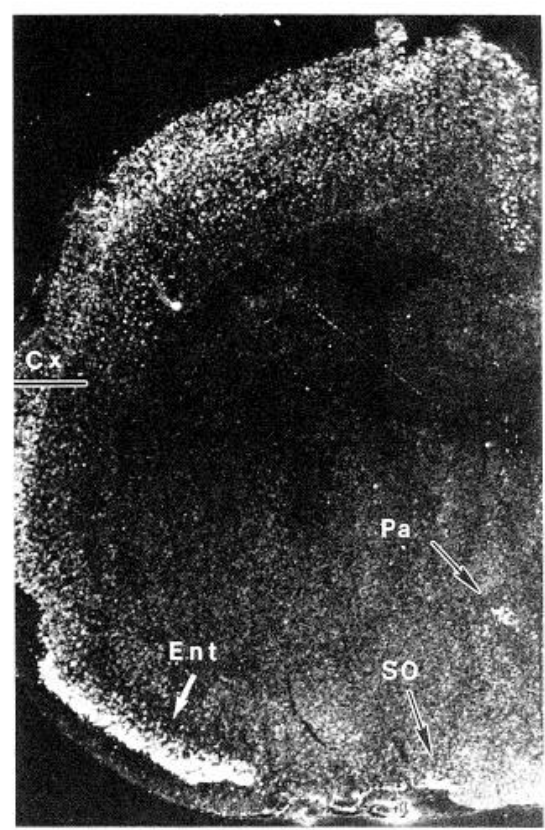



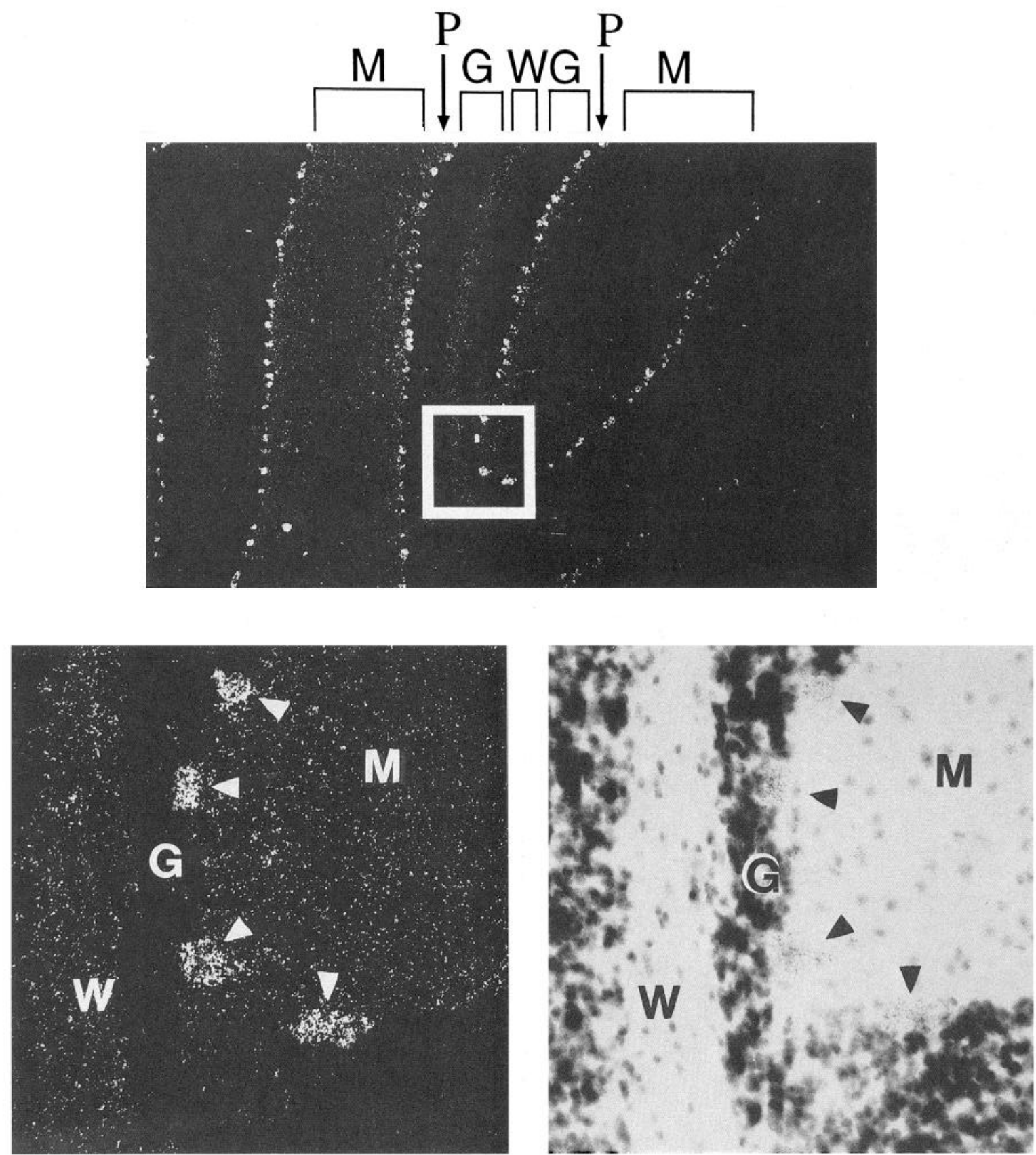

Figure 6. In situ localization of noggin transcripts in coronal section from adult rat cerebellum. The upper panel shows a $35 \times$ magnification of a cerebellum section hybridized to the Noggin probe. Below is the inset area shown at $175 \times$ at left with the corresponding hematoxylin-stained view at right. $G$, Granular cell layer; $M$, molecular cell layer; $P$, Purkinje cell layer; $W$, white matter; the arrowheads point to the layer of Purkinje cells.

\section{Expression of noggin in neuronal and non-neuronal tissues}

The cloning of mammalian noggin genes allowed for the preparation of probes to study the mRNA expression profile of noggin in mammals. Although noggin is currently known only for its inductive actions during early embryogenesis, we were unexpectedly able to detect substantial amounts of noggin expres- sion in the adult. Northern analysis of a variety of RNA samples prepared from adult rat tissues revealed that a main $2.5 \mathrm{~kb}$ noggin transcript was prominently observed in most parts of the central nervous system (Fig. 3A); a minor transcript of about 2 $\mathrm{kb}$, which may correspond to an alternatively spliced version of the main Noggin transcript, was also present in some regions of

Figure 5. In situ localization of noggin transcripts in coronal sections from adult rat brain. Low-power magnification views (10 $\times$ ) of brain sections hybridized to the noggin probe; sections $A-C$ are from anterior to posterior. Pir, Piriform cortex; $O T u$, olfactory tubercle; $C P u$, caudate-putamen; $L S$, lateral septum; Ent, entorhinal cortex; $S O$, supraoptic nucleus; $P a$, paraventricular hypothalamic nucleus; $C x$, cerebral cortex. 
Figure 7. In situ hybridization of a biotin-labeled NOGGIN probe to metaphase cells from phytohemagglutininstimulated peripheral blood lymphocytes. The chromosome 17 homologs are identified with arrows; specific labeling was observed at $17 \mathrm{q} 22$. The inset shows partial karyotypes of two chromosome 17 homologs illustrating specific labeling at 17q22 (arrow). Images were obtained using a Zeiss Axiophot microscope coupled to a cooled charge coupled device (CCD) camera. Separate images of DAPI stained chromosomes and the hybridization signal were merged using image analysis software (NU200 and IMAGE 1.25b).

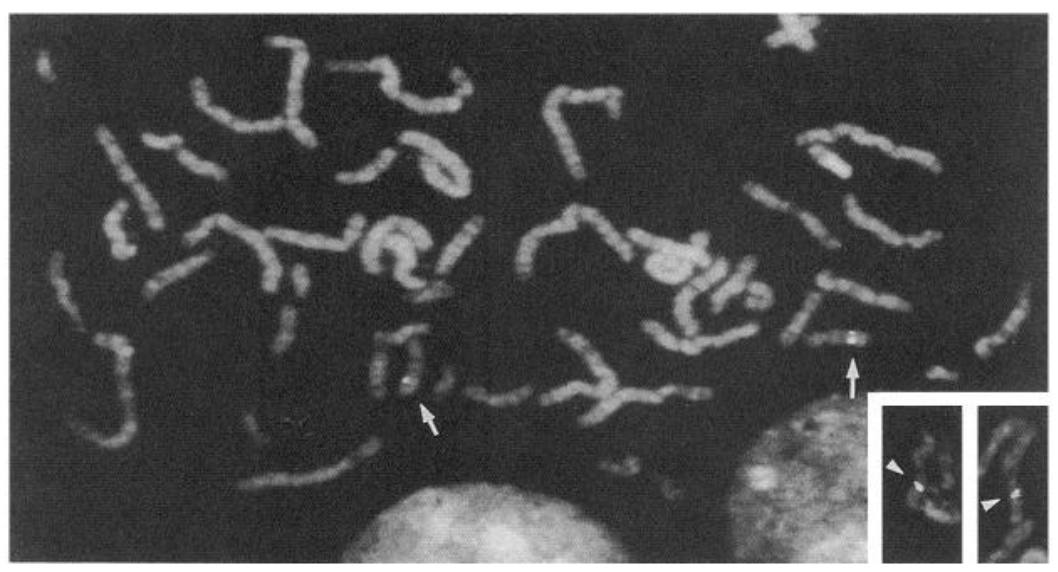

the nervous system. In contrast to the findings in the nervous system, low or undetectable levels of noggin expression were found in peripheral nerve or in non-neural tissues (Fig. $3 A$ ); in non-neural tissues detectable levels were seen in lung, skeletal muscle, and skin. Examination of noggin expression in newborn brain regions as compared to adult brain regions revealed potential developmental differences-for example, in the adult the cerebellum has markedly higher levels of noggin expression than does the hindbrain, while the reverse is true in the newborn. To further examine developmental changes in noggin expression, we analyzed noggin mRNA levels in the brain and spinal cord at different developmental ages (Fig. $3 B, C$ ). In the brain, noggin expression clearly increased, rather steadily, from embryonic day 17 to postnatal day 19 . In contrast, noggin expression in the spinal cord revealed a peak on the day of birth. The earliest age we could detect Noggin transcripts was in RNA prepared from whole embryos at embryonic day 9 (data not shown).

\section{In situ localization of noggin in brain}

Our Northern analysis suggested that noggin, which can promote neural induction and other specifications in the very early embryo, may also act much later in both the developing and the adult CNS. To gain further insight into such potential roles, we attempted to localize noggin expression in the adult brain using in situ hybridization; this analysis was performed on serial coronal sections from anterior to posterior.

Anteriorly, noggin was found to be prominently expressed in the olfactory bulb, which is the first processing station in the olfactory pathway. Noggin is expressed mainly by the middle tufted cells that are scattered in the external plexiform layer of the bulb, and by the large mitral cells (Fig. 4A). The tufted and mitral cells are related neurons whose extensively ramified dendrites make direct synaptic contacts with incoming olfactory nerve fibers at the glomeruli, and which form the main source of projections out of the bulb; the axons of the tufted and mitral cells form the lateral olfactory tract that project to various olfactory areas of the forebrain (Paxinos, 1985). Interestingly, granular cells in the glomerular and inner granular layers, as well as other intrinsic interneurons of the bulb, do not express notable levels of noggin (Fig. $4 A, B$ ).

In the forebrain the piriform cortex, alternatively known as the primary olfactory cortex because it is a main target of olfactory bulb projections, displays conspicuously prominent noggin expression (Fig. 5A,B). The adjacent cerebral cortex also expresses significant levels of noggin, but not nearly as con- spicuously as the piriform cortex except in the region of the entorhinal cortex, which is contiguous to the piriform cortex and represents a caudal extension of the olfactory cortex that also receives substantial olfactory input. There is a hint of a laminar distribution of noggin expression in the cortex, particularly in dorsal regions, with strongest expression in the more superficial layers. The olfactory tubercle, which extends medially from the piriform cortex and is another major projection site for the olfactory bulb, is conspicuous for its lack of noggin expression as compared to the piriform cortex (Fig. 5A,B); this lack of noggin expression may reflect the fact that the tubercle has been suggested to be an extension of the striatum (Paxinos, 1985), that also includes the caudate and putamen, which unlike the cortex all seem to generally lack noggin expression (Fig. 5A). Other parts of the forebrain that express notable levels of noggin include the lateral septal nucleus (Fig. $5 B$ ), and the supraoptic and paraventricular nuclei of the hypothalamus (Fig. 5C); the latter two nuclei contain the neurons which synthesize and deliver to the pituitary, via their axons, vasopressin and oxytocin, and thus comprise the hypothalamo-neurohypophysial system (Paxinos, 1985).

A number of midbrain and brainstem nuclei, most notably the interpeduncular nucleus, express notable levels of noggin (not shown); low levels can also be detected in cells populating regions of the thalamus and hippocampus (not shown). But the most conspicuous levels of noggin mRNA in remaining brain regions is found in the Purkinje cells of the cerebellum (Fig. 6). Interestingly Purkinje cells are somewhat reminiscent of the tufted and mitral cells of the olfactory bulb, in that both are large highly arborized neurons that are the principal relay cells that form the sole projections out of their respective brain regions (Paxinos, 1985). While noggin expression is highly localized to the Purkinje cells in the cerebellum, low levels can also be observed in the white matter and molecular layer, but not in a form that would represent cell perikarya, suggesting the possibility that noggin message is transported to Purkinje cells dendrites and axons. As in the bulb, granular cells and other interneurons in the cerebellum do not express notable levels of noggin.

\section{Chromosomal localization of the human NOGGIN gene}

To localize the human NOGGIN gene, we performed fluorescence in situ hybridization of a biotin labelled genomic $N O G$ GIN probe to normal human metaphase chromosomes. Hybridization of this probe resulted in specific labeling only of chromosome 17 (Fig. 7). Specific labeling of 17q22 was observed 
in four ( 18 cells), three ( 6 cells), or two ( 1 cell) chromatids of the chromosome 17 homologs in 25 cells examined. Of 92 signals observed (92 of $10017 \mathrm{q}$ chromatids from 25 metaphase cells were labeled), $90(98 \%)$ signals were located at $17 \mathrm{q} 22$, and $2(2 \%)$ signals were located at $17 \mathrm{q} 23$. Signal was not observed at any other chromosomal site. We observed specific signal at $17 q 22$ in a second hybridization experiment using this probe. These results suggest that the NOGGIN gene is localized to chromosome $17 \mathrm{q} 22$.

\section{Chromosomal localization of the mouse Noggin gene}

The mouse chromosomal location of the Noggin locus was determined by interspecific backcross analysis using progeny derived from mating of [(C57BL/6J $\times$ Mus spretus $) \mathrm{F}_{1} \times \mathrm{C} 57 \mathrm{BL} /$ $6 \mathrm{~J})]$ mice. This interspecific backcross mapping has been typed for over 1700 loci that are well distributed among all the autosomes as well as the $\mathrm{X}$ chromosome (Copeland and Jenkins, 1991). C57BL/6J and $M$. spretus DNAs were digested with several enzymes and analyzed by Southern blot hybridization for informative restriction fragment length polymorphism (RFLPs) using a cDNA probe. The $15.0 \mathrm{~kb} M$. spretus-specific HindIII RFLP (see Material and Methods) was used to follow the segregation of the Noggin locus in backcross mice. The mapping results indicated that Noggin is located in the distal region of mouse chromosome 11 linked to $\mathrm{Mpo}, \mathrm{Ngfr}$, and Csfg. Although 134 mice were analyzed for every marker and are shown in the segregation analysis (Fig. 8), up to 145 mice were typed for some pairs of markers. Each locus was analyzed in pair wise combinations for recombination frequencies using the additional data. The ratios of the total number of mice exhibiting recombinant chromosomes to the total number of mice analyzed for each pair of loci and the most likely order are: centromer- $M p o-$ 1/134-Noggin-9/136-Ngfr-1/145-Csfg-. The recombination frequencies [expressed as genetic distances in centiMorgans (cM) \pm the SE] are $-M p o-0.8 \pm 0.7-$ Noggin $-6.6+2.1-$ $N g f r-0.7+0.7-C s f g$.

We have compared our interspecific map of chromosome 11 with a composite mouse linkage map that reports the map of many uncloned mouse mutations (Compiled by M. T. Davisson, T. H. Roderick, A. I. Hillyard, and D. P. Doolitle and provided from GBASE, a computarized database maintained at the Jackson Laboratory, Bar Harbor, ME). Noggin mapped in a region of the composite map that lacks mouse mutations with a phenotype that might be expected for an alteration of this locus.

The distal region of mouse chromosome 11 shares a region of homology with the long arm of human chromosome 17 (summarized in Fig. 8). The mapping of NOGGIN to human $17 \mathrm{q} 22$ and mouse 11 extends the syntenic relationship between these two chromosomes.

\section{Discussion}

The remarkable inductive actions of noggin during Xenopus development, including its ability to directly induce ectoderm to form neural tissue, prompted efforts to identify a mammalian version of noggin and to begin to understand if it might have later actions during development or even in the adult. Here we have described human and rodent versions of noggin and their respective chromosomal locations. The mammalian noggins are remarkably conserved in structure as compared to the Xenopus version, and also maintain a similar functional capability in inductive assays on Xenopus embryos. Analysis of noggin expression in rats suggests that this protein plays roles late in the
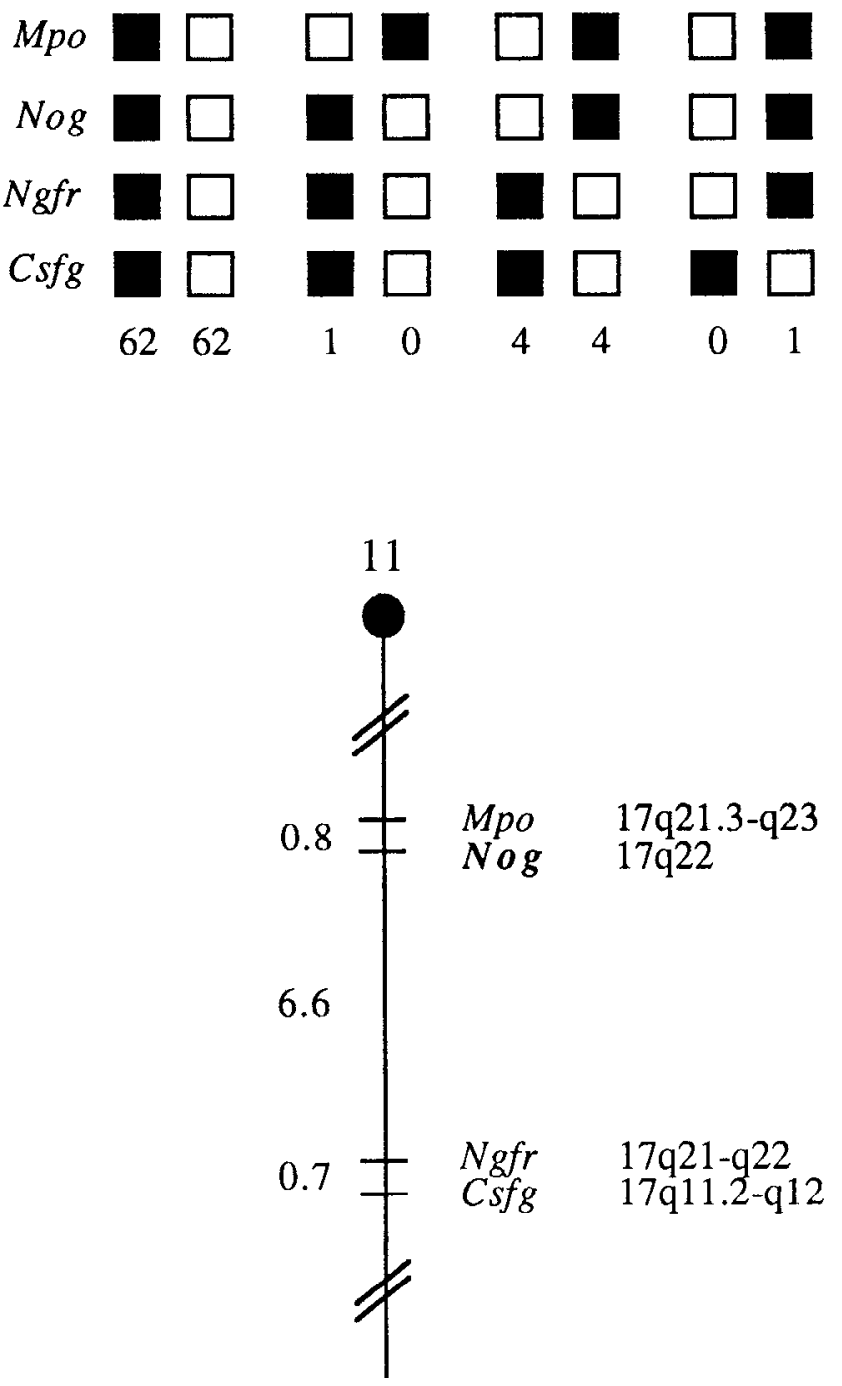

Figure 8. Noggin maps in the distal region of mouse chromosome 11. Noggin (Nog in this figure) was placed on mouse chromosome 11 by interspecific backcross analysis. The segregation patterns of Noggin and flanking genes in 134 backcross animals that were typed for all loci are shown at the top of the figure. For individual pairs of loci, more than 134 animals were typed (see text). Each column represent the chromosome identified in the backcross progeny that was inherited from the $(\mathrm{C} 57 \mathrm{BL} / 6 \mathrm{~J} \times M$. spretus $) \mathrm{F} 1$ parent. The solid boxes represent the presence of a C57BL/6J allele and solid boxes represent the presence of a $M$. spretus allele. The number of offprings inheriting each type of chromosome is listed at the bottom of each column. A partial chromosome 11 linkage map showing the location of Noggin in relation to linked genes is shown at the bottom of the figure. Recombination distances between loci in centiMorgans are shown to the left of the chromosome and the positions of loci in human chromosomes, where known, are shown to the right. References for the map positions of most human loci can be obtained from the GDB (Genome Data Base), a computerized database of human linkage information maintained by The William H. Welsh Medical Library of The Johns Hopkins University (Baltimore, MD).

embryo as well as in the adult. Interestingly, in the adult noggin expression is relatively restricted to the nervous system, and in particular to discrete cell populations within the nervous system. Most notably, high levels of noggin expression are found in mitral and tufted cells in the olfactory bulb, and Purkinje cells in the cerebellum, all of which are large neurons that play major roles in processing and relaying information. These neurons, 
particularly the Purkinje cell, can also exhibit remarkable plasticity in the adult (Ito, 1991), suggesting another possible role for noggin in regulating structural plasticity during spine and synapse induction. Likewise, the presence of high levels of Noggin message in the supraoptic and paraventricular nuclei is of interest because of the demonstrated plasticity in these neurons in adult life, during oxytocin releasc in lactation, and during vasopressin control of regulation (Tweedle et al., 1993).

Although it is conceivable that noggin is modulating the differentiation state of adult neurons in a manner related to its ability to mediate inductive effects in early embryos, it seems likely that the role of noggin in the adult brain will prove to be quite different from its early inductive actions, since it presumably acts on postmilotic neurons in the adult. If this is the case, it would be consistent with findings that many other factors display pleiotropic actions that are important both early in development and later in life. Ciliary neurotrophic factor provides an example of a cytokine that can elicit proliferative responses, growth inhibition, differentiative responses or even death depending on the target cell and the stage of development (Ip et al., 1993); in all cases this cytokine activates the same receptor, but the resulting cell surface signal seems to be differentially interpreted by the responding cell. Wnt-3 provides another example of a developmentally regulated factor that is expressed both early in development during neural plate formation as well as in the mature brain, where it is found in Purkinje cells (Salinas et al., 1994).

While noggin is a secreted protein that may mediate its actions via cell surface receptors on responsive cells, neither the receptor nor the signaling cascade it activales have been characterized. Furthermore, a recent report that noggin exhibits structural similarities with the Kunitz class of protease inhibitors (McDonald et al., 1993) raises the possibility that noggin does not mediate its actions by binding to a cell surface receptor, but rather as a protease inhibitor; protease cascades in Drosophila have been implicated in initiating dorsal-ventral pattern formation (St. Johnston et al., 1992). In addition, recent findings that neural induction in embryos can result from inhibition of transforming growth factor $\beta$ like factors (Hemmati-Brivanlou et al., 1994 a,b) suggests yet more potential modes of action for noggin; it could either act to directly inhibit these factors extracellularly, or indirectly by activating competing intracellular signaling pathways. Insight into the precise molecular mechanism of action of noggin should help better define its physiologic roles both during development and in the adult brain.

\section{References}

Buchberg AM, Brownell E, Nagata S, Jenkins NA, Copeland NG (1989) A comprehensive genetic map of murine chromosome 11 reveals extensive linkage conservation between mouse and human. Genetics 122:153-161.
Copeland NG, Jenkins NA (1991) Development and applications of a molecular genetic linkage map of the mouse genome. Trends Genet 7:113-118.

Davis S, Aldrich, TH, Valenzuela DM, Wong V, Furth ME, Squinto SP Yancopoulos GD (1991) The receptor for ciliary neurotrophic factor. Science 253:59-63.

Green EL (1981) Linkage, recombination and mapping. In: Genetics and probability in animal breeding experiments, pp 77-113. New York: Oxford UP.

Hemmati-Brivanlou A, Kelly OG, Melton DA (1994a) Follistatin, an antagonist of activin, is expressed in the Spemann organizer and displays direct neuralizing activity. Cell 77:283-295.

Hemmati-Brivanlou A, Melton DA (1994b) Inhibition of activin receptor signaling promotes neuralization in Xenopus. Cell 77:273-281.

Ip NY, Yancopoulos GD (1993) Receptors and signaling pathways of ciliary neurotrophic factor and the neurotrophins. Semin Neurosci 5:249-257.

Ito M (1991) The cellular basis of cerebellar plasticity. Curr Opin Neurobiol 1:616-620.

Jenkins NA, Copeland NG, Taylor BA, Lee BK (1982) Organization, distribution, and stability of endogenous ecotropic murine leukemia virus DNA sequences in chromosomes of Mus musculus. J Virol 43: 26-36.

Lamb TM, Knecht AK, Smith WC, Stachel SE, Economides AN, Stahl $\mathrm{N}$, Yancopoulos GD, Harland RM (1993) Neural induction by the secreted polypetide Noggin. Science 262:713-718.

McDonald NQ, Kwong PD (1993) Does Noggin head a new class of Kunitz domain? Trends Biochem Sci 18:208-209.

Paxinos G (1985) The rat nervous system. New York: Academic.

Rowley JD, Diaz MO, Espinosa R, Patel YD, van Melle E, Ziemin S, Taillon-Miller P, Lichter P, Evans GA, Kersey JD, Ward DC, Domer PH, Le Beau MM (1990) Mapping chromosome band 11q23 in human acute leukemia with biotinylated probes: identification of $11 \mathrm{q} 23$ translocation breakpoints with a yeast artificial chromosome. Proc Natl Acad Sci USA 87:9358-9362.

Salinas PC, Fletcher C, Copeland NG, Jenkins NA, Nusse R (1994) Maintenance of Wnt-3 expresion in Purkinje cells of the mouse cerebellum depends on interactions with granule cells. Development 120:1277-1286.

Smith WC, Harland RM (1992) Expression cloning of noggin, a new dorsalizing factor Localized to the Spemann organizer of Xenopus embryos. Cell 70:829-840.

Smith WC, Knecht AK, Wu M, Harland RM (1993) Secreted noggin protein mimics the Spemann organizer in dorsalizing Xenopus mesoderin. Nature 361:547-549.

Spemann H (1938) Embryonic development and induction. New Haven: Yale UP.

Spemann H, Mangold H (1924) Uber Induktion von Embryonanlagen durch Implantation artfremder Organisatoren. Roux's Arch Entwmech 100:599-638.

St Johnston D, Nüsslein-Vollhard C (1992) The origin of pattern and polarity in the Drosophila embryo. Cell 68:201-219.

Stewart RM, Gerhart JC (1990) The anterior extent of dorsal development of the Xenopus embryonic axis depends on the quantity of the organizer in the late blastula. Development 109:363-372.

Tweedle CD, Smithson KG, Hatton GI (1993) Rapid synaptic changes and bundling in the supraoptic dendritic zone of the perfused rat brain. Exp Neurol 124:200-207.

Valenzuela DM, Maisonpierre PC, Glass DJ, Rojas E, Nunez L, Kong Y, Gies DR, Stitt TN, Ip NY, Yancopoulos GD (1993) Alternate forms of rat TrkC with different functional capabilities. Neuron 10 963-974. 